\title{
8
}
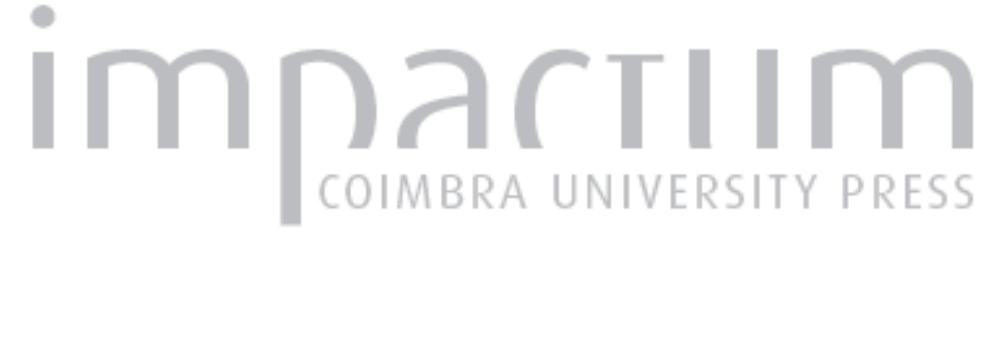

Porque se fazem obras nos museus?: reflexões em torno de um caso

\author{
Autor(es): $\quad$ Redol, Pedro
}

Publicado por: $\begin{aligned} & \text { Instituto de História Económica e Social; Imprensa da Universidade de } \\ & \text { Coimbra }\end{aligned}$

URL

persistente:

URI:http://hdl.handle.net/10316.2/44511

DOI:

DOI:https://doi.org/10.14195/0870-4147_37_19

Accessed : $\quad$ 26-Apr-2023 14:24:43

A navegação consulta e descarregamento dos títulos inseridos nas Bibliotecas Digitais UC Digitalis, UC Pombalina e UC Impactum, pressupõem a aceitação plena e sem reservas dos Termos e Condições de Uso destas Bibliotecas Digitais, disponíveis em https://digitalis.uc.pt/pt-pt/termos.

Conforme exposto nos referidos Termos e Condições de Uso, o descarregamento de títulos de acesso restrito requer uma licença válida de autorização devendo o utilizador aceder ao(s) documento(s) a partir de um endereço de IP da instituição detentora da supramencionada licença.

Ao utilizador é apenas permitido o descarregamento para uso pessoal, pelo que o emprego do(s) título(s) descarregado(s) para outro fim, designadamente comercial, carece de autorização do respetivo autor ou editor da obra.

Na medida em que todas as obras da UC Digitalis se encontram protegidas pelo Código do Direito de Autor e Direitos Conexos e demais legislação aplicável, toda a cópia, parcial ou total, deste documento, nos casos em que é legalmente admitida, deverá conter ou fazer-se acompanhar por este aviso.

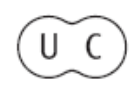




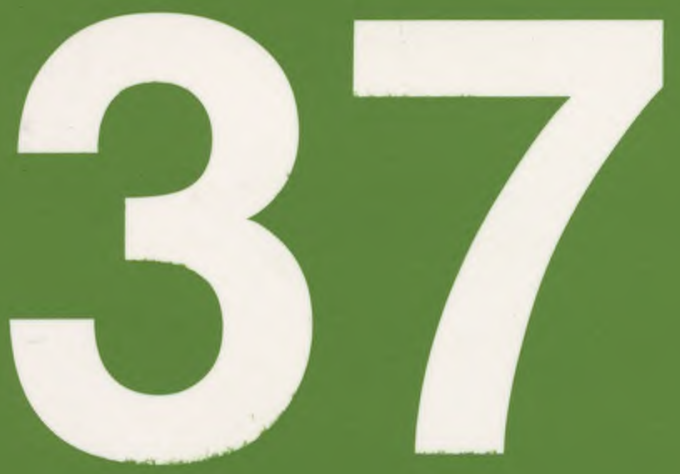

Revista Portuguesa de História

Faculdade de Letras da Universidade de Coimbra Instituto de Historia Econónica e Samial

Coimbra 05 


\section{Porque se fazem obras nos museus? Reflexões em torno de um caso}

PEDRO REDOL'

Director do Museu Nacional de Machado de Castro

O Museu Nacional de Machado de Castro é um exemplo, entre muitos, de sobreposição de memorias, muitas delas deslocadas. À semelhança de outros museus, ocupa edifícios antigos, aos quais se chamou um vasto património colhido em conventos extintos, catedrais e igrejas colegiadas. As colecções foram depois engrossadas por generosas doações de particulares.

Para que achamos que servem os museus?

A missão consagrada dos museus consiste em proporcionar oportunidades de fruição e conhecimento do património que têm à sua guarda. Tal desiderato não pode cumprir-se sem que exista conhecimento daquilo que se mostra, nem tão-pouco sem que se garanta a subsistência do suporte desse conhecimento. Investigar, conservar e divulgar, eis alguns dos atributos do museu, repetidos e hierarquizados até à exaustão por manuais de personalidade cartesiana. $\mathrm{O}$ museu é ele próprio, para um público informado cada vez mais vasto, afinal de contas, entidade veiculadora de um conhecimento classificativo, racionalista, com um * 
equivalente escrito. O museu tem sido - e é, com alguns méritos - uma entidade catalogadora, que gere a quase totalidade do seu tempo em tomo do inventário, esse tão extraordinário quanto enganador instrumento. A ficha de inventário é o bilhete de identidade de uma peça, mas, tal como ele, não diz tudo, nem provavelmente o mais importante, sobre quem identifica.

Os museus contam histórias, oferecem explicações do passado, colocam peças em sequência e estabelecem nexos entre elas. Os museus são discurso, a maior parte das vezes sobre outros discursos, mais ou menos consagrados. Ao converter um programa museológico e proceder à remodelação e ampliação do Museu Nacional de Machado de Castro interrogámo-nos sobre a natureza do discurso que pretendemos adoptar.

Discurso é o fim e o princípio de processos de apropriação do real. Recebido, em linguagem verbal, visual, sonora ou outra, está prestes a ser transformado e reemitido na mesma ou noutra linguagem. Porém, nenhuma linguagem é equivalente a outra, nenhuma delas pode substituir outra. A diferentes linguagens correspondem aptidões cerebrais e psicomotoras diversas, genética e culturalmente complementares, na medida da homeostasia (a que outros chamariam felicidade) do sujeito cognoscente. O Ocidente cristão, uma das grandes culturas do Livro, tem privilegiado a escrita e a linguagem verbal em detrimento da visualidade e esta relativamente a outras formas de conhecimento sensível. A escrita é, para nós, a primeira porta; aquela que abre para o conhecimento de uma peça exposta no museu, através de tabelas ou outras explicações, quantas vezes as que sumariamente foram transcritas para as fichas de inventário a partir de um livro cujo autor não teve muitas oportunidades de conviver com a obra. A popularidade de um processo cognitivo e comunicativo está relacionada com a facilidade que temos no seu exercício, não com as aptidões de que realmente dispomos para o exercitar.

Porque mostra objectos no espaço - essa dimensão de acesso a todo o conhecimento sensível -, o museu tem por vocação primeira motivar a apropriação do real através de todos os canais possíveis, tanto racionais como intuitivos, consciente de que os processos cognitivos são indissociáveis da linguagem e, por conseguinte, da comunicação, isto é, de que não é possível conhecer sem participar, devolvendo a si mesmo ou aos outros um entendimento da interacção com o objecto.

A ideia de espaço é tão difusa quanto a sua intangibilidade. No entanto, é o espaço que, em primeiro lugar, condiciona a percepção e representação do real, designadamente sob a forma de diferentes poéticas. Espaço é o que fica entre o material de construção, inerte ou vivo, é arquitectura ou paisagem. Pode ser tenso ou distendido, alternado em contracções e dilatações, pode ser talhado 
no muro ou simplesmente indicado pela caixa construtiva, centrifugador ou linearmente concorrente, diáfano ou contrastado, reverberante ou surdo. Apercepção do espaço não é independente do tempo, nem resulta exclusivamente da visão. Pode-se dizer que temos impressões características de espaço. Temos também muita dificuldade em traduzir essas impressões em palavras, pois a percepção do espaço é como um sexto sentido que convoca todos os outros.

\section{Que significa requalificar museus?}

Assim, a requalifícação do espaço toma-se na grande prioridade de museus que, como aquele que aqui consideramos, foram acumulando objectos arrancados aos seus contextos funcionais no interior de edifícios antigos, resultantes eles próprios da estratificação de numerosas preexistências. Requalificar o espaço implica experiência relativamente à interacção entre espaço, pessoas e objectos, uma experiência que é exigível tanto aos programadores, por regra o director do museu e os seus colaboradores imediatos, como aos projectistas.

O Museu Nacional de Machado de Castro herdou como instalações o Paço Episcopal de Coimbra, sob o qual a arqueologia viria a descobrir restos das primeiras duas igrejas da invocação de S. João de Almedina, ambas românicas, e do seu claustro, bem como do forum do tempo de Nero, da sua basílica e do monumental criptopórtico que o sustentava. Desde que o Museu foi fundado, em 1911, não pararam as obras de adaptação dos seus edifícios a espaços expositivos informados por diferentes ideais - desde os da educação popular até àqueles que derivaram da consolidação dos estudos de história e crítica de arte. Em particular as que se arrastaram desde a década de quarenta até aos anos setenta do século XX, modificaram significativamente o fácies do conjunto, oferecendo à memória inusitadas referências de monumentalidade. Cabem aqui as transformações que se seguiram à demolição do Arco do Bispo, que ligava o Paço à Sé Nova, e que compreenderam a elevação das alas norte e poente, após a inclusão de portais provenientes do Colégio de S. Tomás e do Convento de Santa Ana nas respectivas fachadas. Deste convento foi trazido um outro portal para a fachada da seiscentista igreja de S. João de Almedina. Para o seio da ala norte viria a colateral de

S. Domingos encomendada pelo tesoureiro da Sé de Coimbra a João de Ruão. Por outro lado, desde os anos vinte que se vinham fazendo importantes descobertas de vestígios ou de partes relativamente íntegras de edifícios mais antigos: primeiramente, o criptopórtico romano; mais tarde, os restos da igreja românica de S. João de Almedina e do seu claustro, remontado em voluntariosa anastilose. 


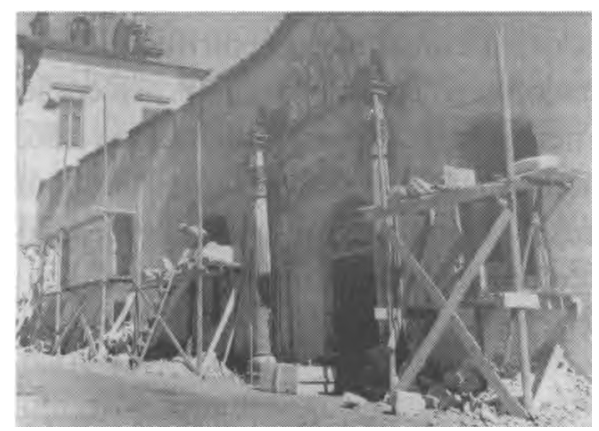

la

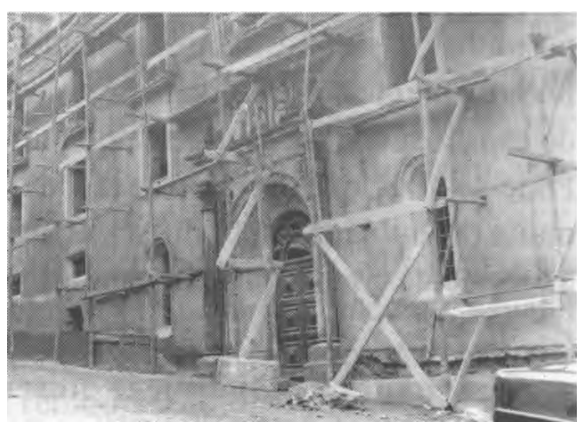

Ib

Fíg. 1 - Fachada norte do Museu Nacional de Machado de Castro: la - após a incorporação do portal do Colegio de S. Tomás (1934-39); Ib - em reconfiguração, nos anos 50-60 do séc. XX

As fachadas norte e nascente do antigo Paço assumiram, para as gerações que nasciam enquanto a sua edificação se concluía, uma aparência decorosa de impossível palácio setecentista, enaltecido de lampejos renascentes e maneiristas que, não sendo convincentes, tão-pouco impeliam a grandes questionamentos. Por trás delas, diversos pisos destinados à administração do Museu, moldaram-se em tomo da capela-mor de S. João e da Capela do Tesoureiro, numa sinuosidade centrifugadora, de desconfortável efeito espacial. Os restos arquitectónicos aqui e além encontrados apareciam associados aos limites físicos de ulteriores configurações espaciais, sem que a sua percepção permitisse identificar inequivocamente o seu carácter de testemunho. Disso são exemplo as grandes sapatas da igreja românica de S. João de Almedina, intrigantemente alinhadas ao centro da sala que flanqueia a igreja seiscentista.

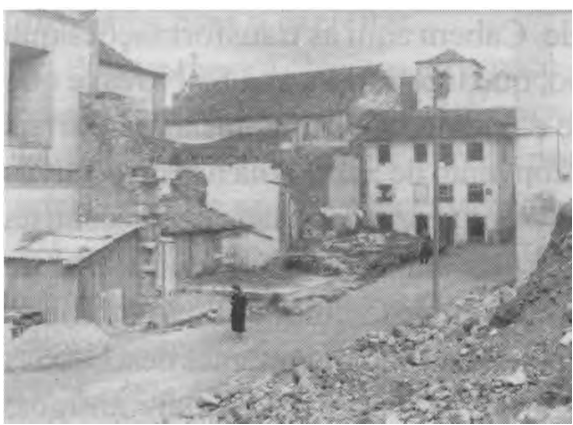

$2 \mathbf{a}$

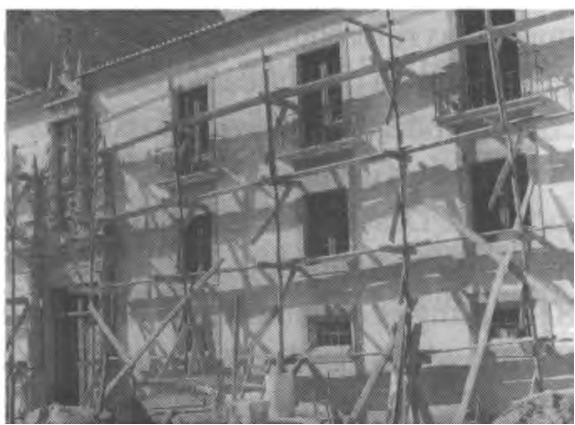

2b

Fig. 2 - Fachada nascente: 2a - Demolição do Arco do Bispo e da Residência Episcopal

(anos 40-50 do séc. $X X) ; 2 b$ - nova construção, incorporando um portal do desaparecido Convento de Santa Ana (anos 50-60 do séc. XX) 


\section{Voltando ao princípio}

A consciência de um objecto de conhecimento tem de ser assumida, num dado momento, para que exista conhecimento. No entanto, ela é mutante e o chamado programa museológico deverá aceitar, desde o princípio, que as suas soluções não são eternas, nem sequer particularmente duradouras. $O$ constante sentido reflexivo da consciência é a condição mais importante para que um programa de ordenamento do território, de arquitectura ou de museologia (as fronteiras entres eles não são rígidas) não fracasse e possua a lucidez suficiente para assumir de forma serena e responsável o agenciamento do espaço através de estruturas mais ou menos duradouras, por um lado, e a necessidade relativamente frequente de reconversão, por outro.

A requalificação da cidade parece ser o objectivo dotado de maior perenidade, no contexto que actualmente informa decisões políticas deste género, sendo portanto inevitável a disponibilização de edifícios e de espaços exteriores que, na forma actualmente pretendida, não existiam (por isso se aceitou requalificar). A fruição e o entendimento do sítio deverão ser facilitados no âmbito desta requalificação, tendo em mente, em primeiro lugar, as necessidades dos utentes, que podem por eles ser sentidas ou corresponder a ideais de cultura. Assim, um museu ou um monumento, por exemplo, não têm de ser apenas o lugar onde todas as facilidades são oferecidas ou vendidas, mas também e sobretudo um território de interacção sensorial e intelectual investido de possibilidades de transcendência relativamente às experiências mais familiares ao visitante.

$\mathrm{O}$ estabelecimento da matéria de intuição/entendimento terá de se fazer sempre com base num conhecimento estabilizado acerca do objecto, na natural ordem dialéctica ascendente/descendente emoção - sentimento - consciência - sentimento - emoção. O insucesso de muitas das soluções museológicas tradicionais deve-se ao facto de se assumir a racionalidade de um determinado grupo social como a racionalidade de todos os grupos de utentes. A única solução para que exista uma plataforma comum à maioria é realmente partir daquilo que é comum a todos, ou seja, da capacidade de sermos impressionados, quer dizer, de termos emoções, ainda que estas possam variar de pessoa para pessoa. Satisfeita a condição de uma experiência individual, toma-se possível a apropriação de uma segunda ordem de representação do real, em geral mais racional e consciente, sob a forma discursiva. A oportunidade de formação de emoções encontra-se normalmente através de complexas experiências multi-sensoriais, nomeadamente a de espaço, que, como vimos, processa impressões visuais, auditivas, olfactivas, acústicas e tácteis, prescindindo ou não de um ou de mais canais de percepção. 
Aquilo que hoje consciencializamos a respeito da nossa relação com o mundo depende do estado da própria ciência. Os princípios de comportamento acima enunciados são hoje em dia matéria de estudo da neurobiologia que nos permite saber como se formam no cérebro tanto as emoções como a consciência. Este paradigma tem raízes longínquas nos idealismos setecentistas, aí compreendido o de Kant, e raízes mais próximas na psicologia da percepção. Como qualquer paradigma, será válido enquanto outro não o substituir, trazendo como novidade justamente a reabilitação da emoção face a séculos de tirania racional. É importante esclarecer que reabilitar a emoção não significa estar contra a razão, ou, por outras palavras, a consciência. Essa ideia implica a descomplexação do estatuto racional humano, fundando-o na necessidade biológica de sobreviver, sem porém explicar a sua origem última, que, a menos que se verifique entretanto uma extraordinária revolução no domínio da física, continuará a ser matéria da metafísica.

Apesar deste paradigma e da nossa capacidade de consciencializar que a percepção do real é um virtual jogo de espelhos borgiano, em que por trás de uma aparência está sempre outra, o mesmo é dizer, em que só conhecemos aquilo que existe dentro de nós e que está em relação com o nosso corpo, parece afirmar-se nos últimos tempos um neopositivismo de pendor filológico que acredita ingenuamente numa realidade autónoma relativamente ao sujeito do conhecimento. Mais concretamente, esta atitude intelectual tem dado origem a acérrimos ataques à convicção de que a reabilitação arquitectónica requer não apenas interpretação das preexistências como ainda intervenção criativa. Tanto os escritos de Paolo Marconi como, entre nós (e na sua esteira), o arquitecto e universitário José Aguiar, têm vindo a condenar a criação e a favorecer exclusivamente a anastilose. Semelhante atitude é altamente merecedora de reflexão.

No princípio do século XX, Benedetto Croce recordou-nos de como é ingénuo pensar que se pode conhecer sem julgar. Outros pensadores como Lionello Venturi, Cesare Brandi e, muito mais recentemente, Giovanni Carbonara, reiteraram esta ideia e dela fizeram derivar os princípios metodológicos necessários, por um lado, à história e crítica de arte (tão caros, como sabemos, por exemplo, a Giulio Cario Argan) e, por outro lado, ao restauro - cuja teoria correspondente ficou conhecida por "restauro crítico". Uma tal corrente de pensamento inscreve-se naturalmente num conjunto de neo-idealismos que perpetuam a convicção antiga na transcendentalidade da arte.

Hoje, a ciência afirma que aquilo que é transcendente é a arte de viver, de nos adaptarmos constantemente, por meio das nossas emoções; assim como crónica é a nossa incapacidade de desenvolver a consciência através de um exercício que parta da emoção. Naturalmente as dificuldades acentuam-se em culturas não holísticas e de especialidade como é a nossa. A própria transformação do 
patrimonio em matéria de especialidade encerra perversões que há muito Françoise Choay se encarregou de acusar.

Contas feitas, parece que o novo positivismo não augura grande futuro ao património, ele próprio sendo já um conceito imbuído da ideia de posse e, portanto, nefasto ao conhecimento e à insuspeita prodigalização das suas conquistas aos seres humanos que delas possam beneficiar. $\mathrm{O}$ respeito meramente conservacionista é, nas palavras de F. Choay, uma atitude umbilical e narcísica, que não comporta em si mesma quaisquer perspectivas de transformação e que só pode ser entendida em face do pavor perante a rápida mudança da paisagem à nossa volta. De facto, uma das particularidades do ser humano face a outros animais é a sua capacidade de recordar emoções e sentimentos e não tanto a de possuir consciência (ainda que com características diversas, outros seres são dotados de consciência), sendo sempre, por esta razão, o valor de memória inerente ao famigerado património um dado da afectividade. A memória permite seleccionar as experiências boas e más, isto é possuir padrões de valores. E sabemos quanto o medo impede o bom funcionamento da vida.

Os problemas da paisagem - chamemos-lhe assim em vez de "património" não são geríveis numa base conservacionista porque a vida muda e a refuncionalização exige transformações. Se semelhantes mudanças nos permitirem uma saudável viagem de autodescoberta, nada teremos a temer. Resta acrescentar que o restauro crítico nem esqueceu a necessidade da análise arqueológica, de pendor filológico, no julgamento das preexistências, nem a anastilose no plano operativo. Estamos convencidos de que o conservacionismo que se vai de novo experimentando constitui, face à alternativa crítica, uma atitude que poderá, sem dúvida, beneficiar o conhecimento e o domínio de saberes tradicionais na arquitectura, que não tem justificação para se perder (justamente porque os conservacionistas o entendem criticamente como mais qualificado), mas do ponto de vista filosófico representa uma grande ingenuidade e uma fuga para a frente, altamente perniciosa aos próprios valores que defende.

\section{Requalificar o Museu Nacional de Machado de Castro}

A ampliação e requalificação do Museu Nacional de Machado de Castro tomou-se, na década de 1990, uma prioridade para o Instituto Português de Museus. Tendo-lhe sido cometida a tarefa de produzir o respectivo programa base, a nova direcção ${ }^{1}$ empreendeu uma alteração profunda dos serviços, quer ao

${ }^{1}$ Adília Alarcão tomou posse do lugar de Directora a 5 de Março de 1999 e manteve-se em funções até 4 de Março de 2005. 
nível interno, quer ao nível das relações com o exterior. Justificou-se tal iniciativa não só para reabilitar, a curto prazo, a imagem da instituição, mas, sobretudo, como processo de avaliação das colecções, das potencialidades do edifício e do significado que este museu tem para a comunidade local. Depois de um período de oito meses de encerramento ao público, a instituição abria as suas portas, em Dezembro de 1999, com a exposição Reencontro com o Museu e uma proposta consistente de iniciativas.

Em Janeiro de 2004, após quatro anos de experimentação, o Museu fechava de novo, parcialmente, ao público, encerrando totalmente no ano seguinte, com vista à implementação de um vasto projecto de ampliação e requalificação do conjunto de edifícios que integram o Museu, classificado desde 1910 como monumento nacional. Trata-se de uma ousada proposta de intervenção que propiciará aos objectos a expor relações formais mais adequadas com o espaço envolvente, recuperando valores fundamentais das preexistências arquitectónicas ${ }^{2}$.

O projecto de requalificação, da autoria de Gonçalo Byme, reflecte, por um lado, as necessidades funcionais decorrentes do entendimento do museu como espaço público que pretende oferecer a todos oportunidades iguais (embora este não seja um problema que o museu possa resolver unicamente per se), e, por outro, o entendimento crítico do edificado, clarificando as noções de objecto, preexistência arquitectónica e obra nova. O critério basilar para a definição destas noções foi a ideia de autenticidade, inerente à de obra de arte na acepção neo-idealista. Uma preexistência arquitectónica é, por definição, criadora genuína de espaço dotada de qualidades estéticas (isto é, capaz de reacender emoções, já por outros consciencializadas), podendo articular-se mas nunca confúndir-se com outra preexistência da mesma natureza. As ruínas são entendidas como vestígios de semelhantes preexistências que assumem um carácter essencialmente documental. Partes de edifícios de proveniência diversa equivalem-se com os objectos das vastas colecções do Museu, merecendo encenação reveladora dos intrínsecos valores estéticos e documentais, assumida porém como juízo, passível, enquanto tal, de vir a ser substituído por outro juízo. O entendimento do edifício e dos objectos a expor é unitário e aberto, na medida em que a obra nova deve possuir qualidades que permitam reconhecê-la como obra de arte.

A componente de obra nova desta intervenção aplicar-se-á à ala norte do edifício actual, implicando a demolição das construções levantadas entre os anos 40 e 70 do século passado. As fachadas exteriores correspondentes serão

2 ALARCÃO, Adília Moutinho, BYRNE, Gonçalo, "O projecto de remodelação do Museu Nacional de Machado de Castro de Coimbra", Cursos sobre el Património Histórico - 5. Actas los XI Cursos Monográficos sobre el Património Histórico (Reinosa, Julho 2000), Universidad de Cantábria, Reinosa, 2001. 
cegadas, pela maior parte, das aberturas que criaram um falso arquitectónico e o portal de S. Tomás desprovido da sua função de passagem, inscrevendo-se na fachada norte como objecto merecedor de contemplação. No interior, a cota do pavimento descerá ao nivel do claustro medieval, passando o espaço a ser polarizado pela Capela do Tesoureiro, ritualizada por urna nave ampla e luminosa. Avistada do exterior, desde sul-sudeste, esta edificação reafirmará, em claro e inequívoco recorte, a silhueta do antigo Paço Episcopal, conservado na sua qualidade doméstica.

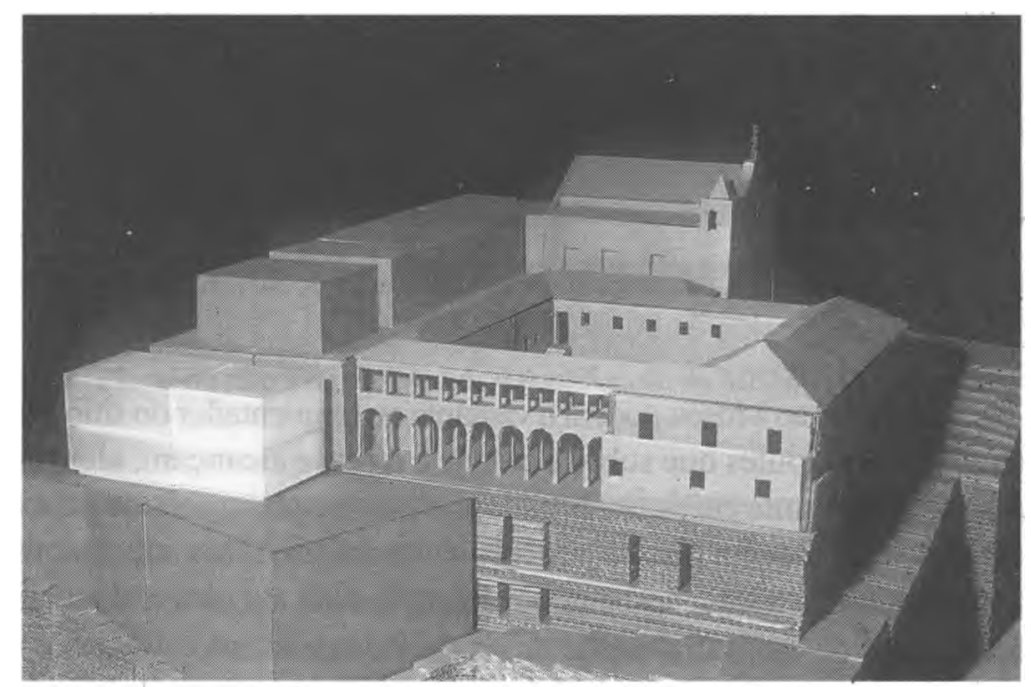

Fig. 3 - Maquete do projecto de requalificação do Museu Nacional de Machado de Castro, da autoría de Gonçalo Byme (2001)

A ruina das casas outrora adjacentes à fachada poente abriu uma ferida indelével no centro histórico que deu pretexto a novas investigações arqueológicas. Descobriu-se uma fonte monumental romana na base dessa fachada do forum, ruída em data indeterminada do período medieval. No gaveto do Beco das Condeixeiras, encontrou-se o limite lateral norte do decumanus maximus, bordejado de algumas construções, sob as quais passa a cloaca maxima, à semelhança do que se verifica no canto sudeste do edifício do Museu. Estes vestígios serão preservados e apresentados aos passantes e visitantes. O terreno maior, a poente, será ocupado por um grande edifício composto por um volume irregular de quatro pisos, a que se sobrepõe outro, paralelepipédico, de dois pisos, alinhado com a ala norte do edifício antigo, ao qual ficará ligado. A fachada do forum será evocada através de uma monumental malha metálica. 
No gaveto será construído o bloco destinado aos serviços técnicos e administrativos do Museu, ligado subterraneamente ao edifício anterior.

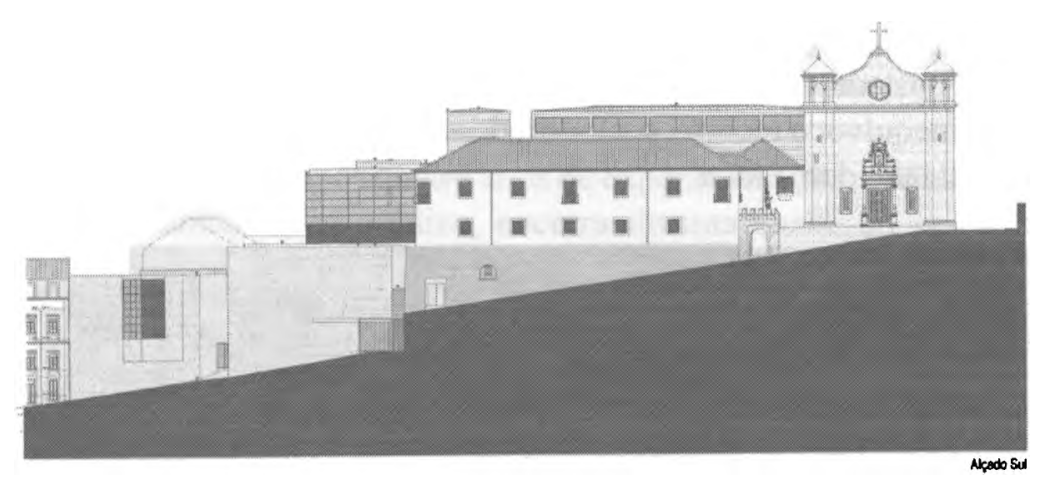

Fig. 4 - Alçado da fachada sui do projecto de requalificação do MNMC (G. Byme, 2001)

No piso de acesso ao Museu poderá o visitante ou frequentador do sitio desfrutar livremente dos horizontes que sobre a cidade e o rio se alcançam, além de vir a ter à sua disposição uma cafetaria, uma loja e uma pequena sala de exposições temporárias. Neste mesmo piso se poderão obter informações sobre a oferta de circuitos, adquirir bilhetes, apreciar as colecções de escultura devocional e arquitectónica, e de epigrafia medievais e do Renascimento, além dos restos da igreja e claustro medievais de S. João. Alternativamente poderá iniciar-se a visita pelo criptopórtico e pela história conhecida de Aeminium. A visita continua, no bloco poente, com escultura nacional de terracota e madeira policromada, escultura e pintura flamengas, avançando depois, no bloco polarizado pela Capela do Tesoureiro, para as colecções de pintura portuguesa, ourivesaria, joalharia e cerâmica. Dada a uniformidade, volume e importância destas colecções e da de escultura, optou-se pela sua apresentação cronológica em galerias completamente novas que proporcionam condições de grande clareza espacial, permitindo pontualmente a correlação temática e, para as chamadas artes decorativas, a associação tipológica.

Uma das salas reformadas por D. Francisco de Lemos, já no antigo Paço, dará motivo à apresentação de desenhos de arquitectura e outras peças relacionadas com a reforma da Universidade de Coimbra de que foi executor. Seguir-se-ão paramentos e a capela do Bispo, sucedendo-se, até ao final do circuito, associações de objectos que tematizam as artes decorativas civis que têm por pano de fundo o mobiliário e os tapetes, focando a influência formal e 


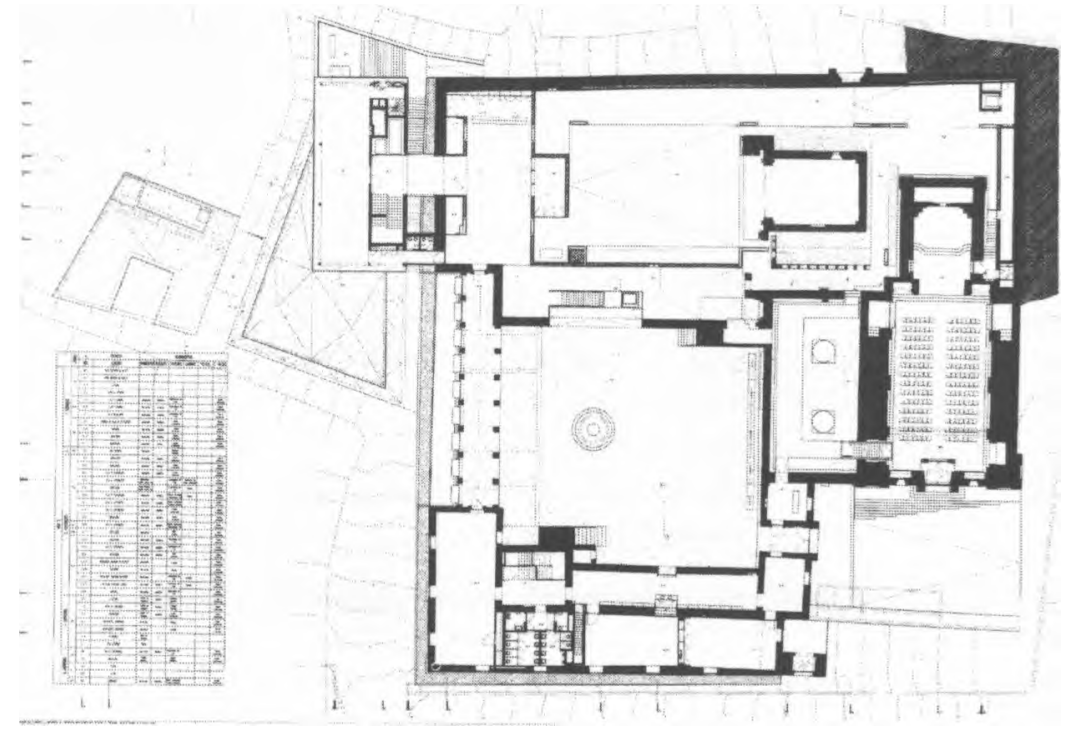

Fig. 5 - Planta do piso 0 do projecto de requalificação do MNMC (G. Byme, 2005)

técnica islámica e o exotismo oriental, já antes abordados na cerâmica. Uma passagem intermédia pela produção nacional dos séculos XVII e XVIII conduzirá ao mobiliário e aos marfins indo-portugueses e ao mobiliário Namban, terminando a visita em duas salas dedicadas às colecções chinesas. $\mathrm{Na}$ componente residencial do Paço, os ambientes domésticos serão assim evocados sem rigorosa recriação formal, não ficando a faltar o gabinete de curiosidades orientais. O percurso concluir-se-á numa sala voltada a poente onde se poderá obter mais informação sobre o que se viu e sobre a história da cidade, podendo igualmente sair-se ao piso superior da loggia.

O Museu disporá ainda de uma galeria de exposições temporárias, encastrada no seio do criptopórtico, bem como de reservas e espaços destinados a conservação e restauro, nos andares inferiores do edifício grande que será construído a poente. 